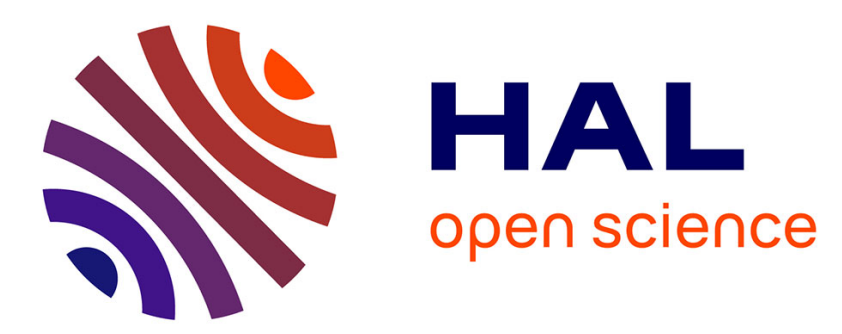

\title{
A numerical investigation of the effects of ice accretion on the aerodynamic and structural behavior of offshore wind turbine blade
}

Oumnia Lagdani, Mostapha Tarfaoui, Mourad Nachtane, Mourad Trihi, Houda Laaouidi

\section{To cite this version:}

Oumnia Lagdani, Mostapha Tarfaoui, Mourad Nachtane, Mourad Trihi, Houda Laaouidi. A numerical investigation of the effects of ice accretion on the aerodynamic and structural behavior of offshore wind turbine blade. Wind Engineering, 2021, 45 (6), pp.0309524X2098322. 10.1177/0309524X20983220 . hal-03104242

HAL Id: hal-03104242

https://hal-ensta-bretagne.archives-ouvertes.fr/hal-03104242

Submitted on 13 Apr 2021

HAL is a multi-disciplinary open access archive for the deposit and dissemination of scientific research documents, whether they are published or not. The documents may come from teaching and research institutions in France or abroad, or from public or private research centers.
L'archive ouverte pluridisciplinaire HAL, est destinée au dépôt et à la diffusion de documents scientifiques de niveau recherche, publiés ou non, émanant des établissements d'enseignement et de recherche français ou étrangers, des laboratoires publics ou privés. 


\title{
A numerical investigation of the effects of ice accretion on the aerodynamic and structural behavior of offshore wind turbine blade
}

\author{
Oumnia Lagdani' $(1)$, Mostapha Tarfaoui ${ }^{2}$, Mourad Nachtane ${ }^{3}$, \\ Mourad Trihi' and Houda Laaouidi'
}

\begin{abstract}
In recent years, several wind turbines have been installed in cold climate sites and are menaced by the icing phenomenon. This article focuses on two parts: the study of the aerodynamic and structural performances of wind turbines subject to atmospheric icing. Firstly, the aerodynamic analysis of NACA 4412 airfoil was obtained using QBlade software for a clean and iced profile. Finite element method (FEM) was employed using ABAQUS software to simulate the structural behavior of a wind turbine blade with $100 \mathrm{~mm}$ ice thickness. A comparative study of two composite materials and two blade positions were considered in this section. Hashin criterion was chosen to identify the failure modes and determine the most sensitive areas of the structure. It has been found that the aerodynamic and structural performance of the turbine were degraded when ice accumulated on the leading edge of the blade and changed the shape of its profile.
\end{abstract}

\section{Keywords}

Airfoil icing, numerical analysis, BEM, Hashin criteria, FEM, composite wind turbine blade

\section{Introduction}

Wind turbines located in cold climate areas have interesting advantages related to increasing air density but have to maintain their operation under icing condition because of the important drop in the lift to drag ratios of iced surfaces (Han and Palacios, 2012; Jha et al., 2012). Icing phenomenon is initiated when a supercooled water droplet suspended in the air freeze upon contact with a surface that permits ice to form on the rotor blade (Liu et al., 2018), causing a severe effect on the aerodynamic performance, resulting in a $30 \%$ lift decrease coupled with a $50 \%$ improvement in drag (Zanon et al., 2018). Power losses resulting from ice accumulation can be strongly influenced by location, wind turbine dimensions and meteorological conditions (Stoyanov and Nixon, 2020). Reduction of airfoil performance due to ice accumulation must be well understood to satisfy safety standards. The icing and aerodynamic physics associated with the movement of the rotor in an icing area is a subject of growing attention (Brown, 2013).

Multiple studies in recent years have analyzed the impact of ice formation on the aerodynamic and structural behavior of offshore wind turbine blade. Jin and Virk (2019a) identified the effects of icing on the aerodynamic

\footnotetext{
'Laboratory for Renewable Energy and Dynamic Systems, FSAC-UH2C, Casablanca, Morocco

${ }^{2}$ ENSTA Bretagne, FRE CNRS 3744, Institut de Recherche Dupuy de Lôme, Brest, France

${ }^{3}$ University of Bordeaux, CNRS, Arts et Metiers Institute of Technology, Bordeaux INP, INRAE, I2M Bordeaux, Talence, France

Corresponding authors:

Oumnia Lagdani, Laboratory for Renewable Energy and Dynamic Systems, FSAC-UH2C, Faculté des Sciences Aïn Chock Km 8 Route d'El Jadida, Casablanca 20100, Morocco.

Email: Oumnialagdani@gmail.com

Mostapha Tarfaoui, ENSTA Bretagne, FRE CNRS 3744, Institut de Recherche Dupuy de Lôme, F-29200 Brest, France.

Email: mostapha.tarfaoui@ensta-bretagne.fr
} 
characteristics of DU96 wind turbine blade profiles. Numerical and experimental analyses were performed for glaze and rime ice conditions using respectively icing tunnel method and computational fluid dynamics (CFD). It proved a good agreement between them and showed that a deterioration of the aerodynamic performance of the blades is more important in case of glaze ice than the profile of rime ice. The same authors (Jin and Virk, 2019b) also examined the impact of ice accumulation on the aerodynamic performance of two different profiles in dry and wet ice conditions. The tests showed that the accumulation of ice is more complex for the $\mathrm{S} 832$ profile for wet ice conditions $(15 \%-20 \%)$ and the S826 airfoil $(5 \%-10 \%)$. While for dry ice conditions, ice formation is prolonged over the chord length to about $25 \%$ for each of the two profiles. Shu et al. (2018) addressed the problem of ice formation and analyzed the power characteristics of a $300 \mathrm{~kW}$ wind turbines in a natural icing area. Using the image processing method, it has been reported that severe structural damage is caused by the thickness of ice which increases strongly from the root to the center of the blade and then gradually until it reaches the tip of the geometry. Ibrahim et al. (2018) examined the effect of blade design on ice accumulation for all of NREL aerodynamic profiles, it was demonstrated that the thickness of the blade and its placement had a very important impact and that ice loads increased significantly with the thickness of the blades. They also reported that the loss of lift coefficient due to the accumulation of ice was between $10 \%$ and $65 \%$ and varied according to the shape of the accumulated ice. Lamraoui et al. (2014) were interested in the influence of atmospheric icing on wind turbine production. They found that under icing conditions, the greatest aerodynamic degradation was found in the external surface of the blade beginning at the radial position $r / R=0.8$ toward its tip, resulting in a loss of power generation. The researchers added that the double-horn-shaped ice caused the greatest aerodynamic degradation and that $85 \%$ of the energy production was produced by the section situated at $60 \%$ of the blade to the tip. Using an ice accumulation prediction methodology combined with the Blade Element Momentum method, Yirtici et al. (2017) worked on optimizing the wind turbine blade profiles to minimize ice accumulation. It has been found that the aerodynamic performance of the iced blade has been considerably improved. It was also noted that the power drops decreased at all wind speeds up to $15 \mathrm{~m} / \mathrm{s}$ and at higher ice exposition times. Homola et al. (2011) calculated power performance losses caused by ice formation on a $63 \mathrm{~m}$ long NREL wind turbine blade using the CFD and BEM method. Analyses were done on five different sections of the blade and found that its end (section E) accumulated the most ice because of the high wind speed, where the value of the efficiency of the local collection was 0.43 while at the center of the blade (section C) had a value of 0.13 . Hudecz et al. (2013) operated an experimental and numerical analysis to visualize the effects of ice accretion on a section of the NACA 64-618 profile. They found that the coefficient of lift decreased and the coefficient of drag increased once the ice had formed. Ebrahimi et al. (2016) conducted experimental studies on an NLF-0414 profile under well-defined icing conditions to study the degradation of its aerodynamic performance. It was determined that the accumulation of double-horn ice strongly altered the aerodynamic characteristics of the profiles and that the size of the separation bubble on the top side increased with the angle of attack, in contrast to the one located at the bottom surface.

In the present work, a numerical investigation of the influence of ice formation on the aerodynamic and structural behavior of offshore wind turbine blade has been performed. To evaluate the change in aerodynamic characteristics of the ice profile, a numerical test was performed at different angles of attack using QBlade software and structural analysis is presented using ABAQUS software based on the Finite Element Method (FEM).

\section{Aerodynamic performance analysis}

\section{Qblade software validation}

The aerodynamics of the two-dimensional NACA 0012 profile was first studied, Figure 1. The calculation was performed using Qblade which is a free software dedicated for the simulation and conception of wind turbines and employs the Blade Element Momentum (BEM) theory to determine the lift and drag coefficient of the airfoil (Nachtane et al., 2019, 2020b). In our case, each test was executed at a constant Reynolds number of $10^{6}$ at a density of $1.225 \mathrm{~kg} / \mathrm{m}^{3}$. The coefficients of lift and drag are obtained at multiple angles of attack and are compared with the CFD method conducted by Yilmaz et al. (2018) and the AERTS experimental facility of Brown (2013) for a NACA0012 profile.

Figure 2 represents the graphical interpretation of the numerical and experimental results of lift and drag coefficients of the NACA 0012 profile as a function of the angle of attack (AoA). In all these tests, the aerodynamic coefficients are calculated for a unit chord length of the un-iced profile.

The lift curves extracted from Qblade correlate with the experimental and CFD data very well, in contrast to the coefficient of drag as indicated above the results obtained coincide more closely with the experimental data. 


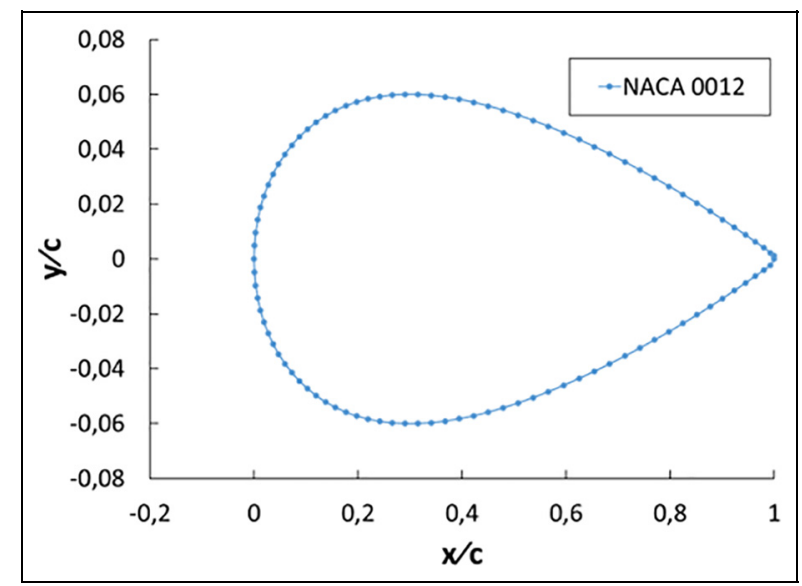

Figure I. NACA 0012 airfoil.

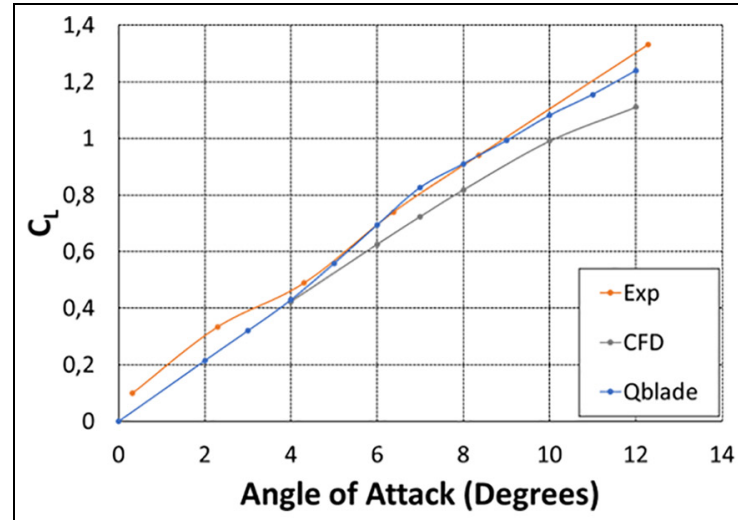

(a) Lift curve

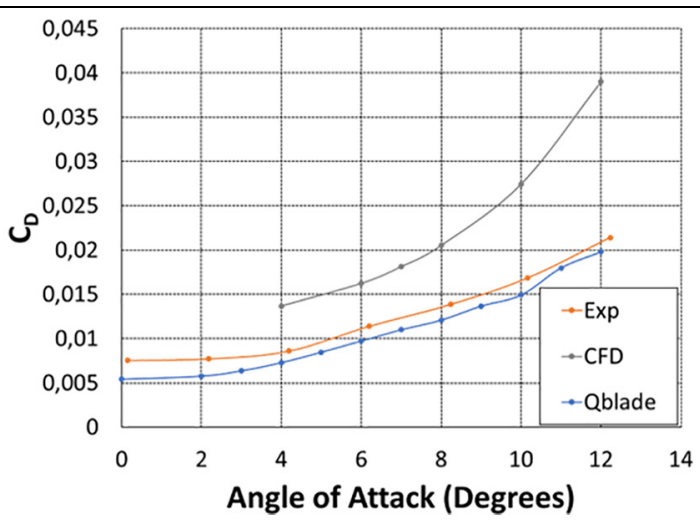

(b) Drag curve

Figure 2. Verification of Qblade code with experimental results and CFD for NACA00I 2 profile, $\operatorname{Re}=10^{6}$.

The aerodynamic lift and drag increase with angle of attack. At 0-degree, Qblade lift coefficient is zero because the test model is using NACA 0012, which is symmetrical and the experimental value is 0.0993 . However, the drag coefficient of Qblade and experimental values of NACA 0012 profile are 0.0053 and 0.0075 , respectively. In general, it can be concluded that there is a good correlation between the numerical values obtained for the NACA 0012 airfoil and the experimental data, confirming the validity of the numerical solutions at the same Reynolds number.

\section{Choice of the profile}

Figure 3 illustrates the change of the optimum power coefficient $\left(C_{\mathrm{P}}\right)$ as a function of the tip-speed ratio (TSR). It can be seen that the value of $C_{\mathrm{P}}$ rises quickly with TSR until it reaches its optimal value, after which it progressively reduces. It is found that NACA 4412 type blades deliver greater power output than the others, making it an ideal aerodynamic profile for wind turbine applications (Tarfaoui and Shah, 2013).

Taking into account the icing phenomenon, the basic profile has been modified in two different forms (Ice1, Ice2) to study the impact of ice formation on the aerodynamic wind turbine blades performance. The shape of the airfoil is shown in Figure 4, where the basic profile has been assigned as "Clean" while the first iced profile on the leading edge is "Ice 1 " and the second is named "Ice 2." 


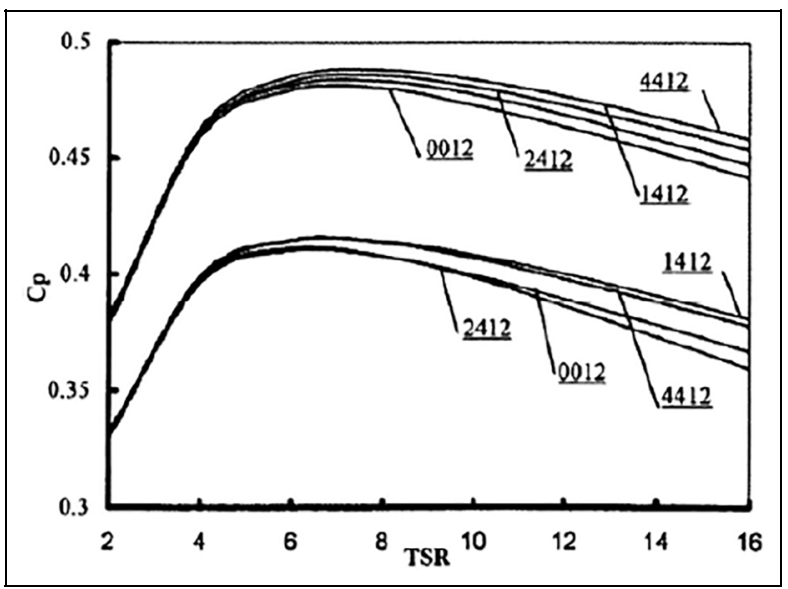

Figure 3. Evolution of $C_{P}$ as a function of TSR for a three-bladed rotor of NACA type with four digits.

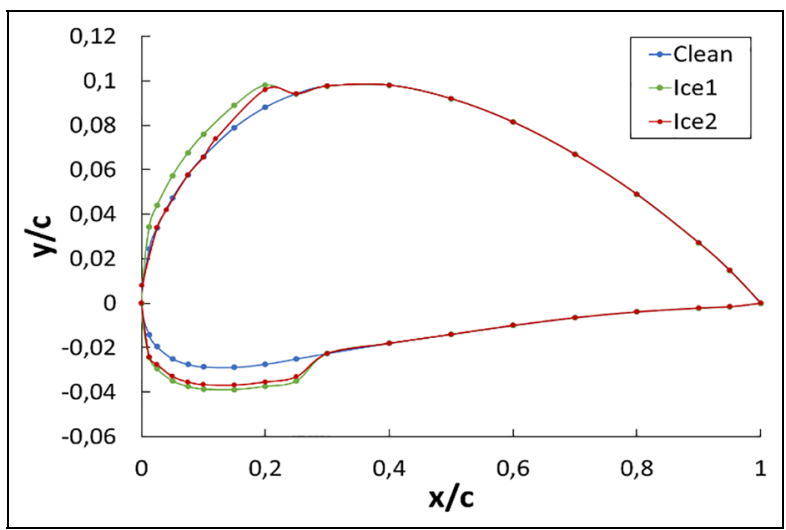

Figure 4. Clean and accreted ice shapes of NACA 4412.

\section{Geometric modeling of rotor}

The tests models are based on a three-blade propeller, where the different sections for the wind turbine blade are listed in Table 1.

Although the icing and non-icing profiles are the same for all the 18 sections of the turbine blade. Figure 5 shows that the radial sections are thin near the tip, while their thicknesses increase at a smaller radius to eventually turn circular at the blade root.

\section{Aerodynamic characteristics of NACA 44I 2 profile}

The NACA 4412 aerodynamic profile for a blade with and without ice is selected and analyzed for a Reynolds number equal to $10^{5}$ and wind speed of $25 \mathrm{~m} / \mathrm{s}$ in the QBlade software. The aerodynamic coefficients are calculated at angles of attack starting from $-6^{\circ}$ to $20^{\circ}$. Figure 6 presents the lift and drag coefficient plots for clean and frozen NACA 4412 airfoils where ice accumulation is concentrated on the leading edge (Ice1 and Ice2). Iced shapes have a strong effect on the aerodynamic characteristics of the airfoil. It can be seen that for large angles of attack. The area enclosed between the lift coefficients of the iced and clean airfoils increases. While the distance between the drag coefficients curves decrease. It is also observed that lift and drag characteristics were both created even at a negative angle of attack.

From Figure 7, the lift-drag ratio $\left(C_{L} / C_{D}\right)$ of NACA 4412 airfoil suddenly decreases when ice forms on its leading edge. The clean profile showed the best performance with a value of 55.115 at an attack angle of $8^{\circ}$ while for Ice 1 and Ice 2, the lift-drag ratios are respectively 31.934 and 34.624 at $6.5^{\circ}$. 


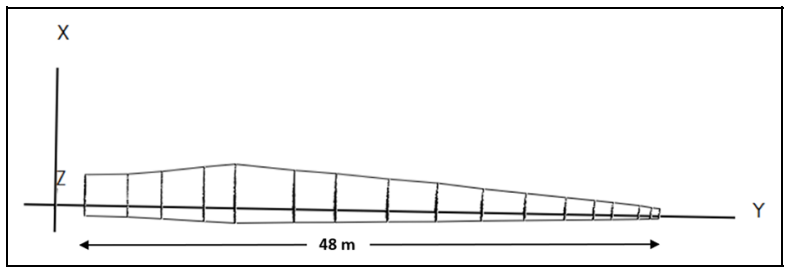

Figure 5. Blade structure with clean NACA 4412 airfoil (XY-plane).

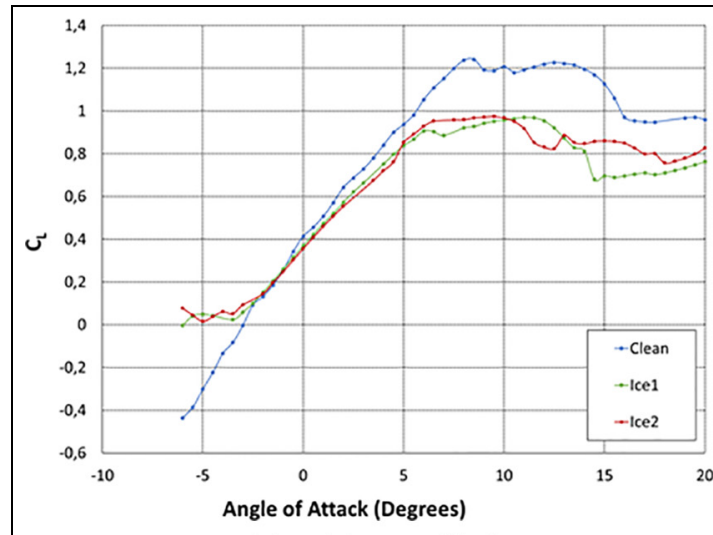

(a) Lift coefficient

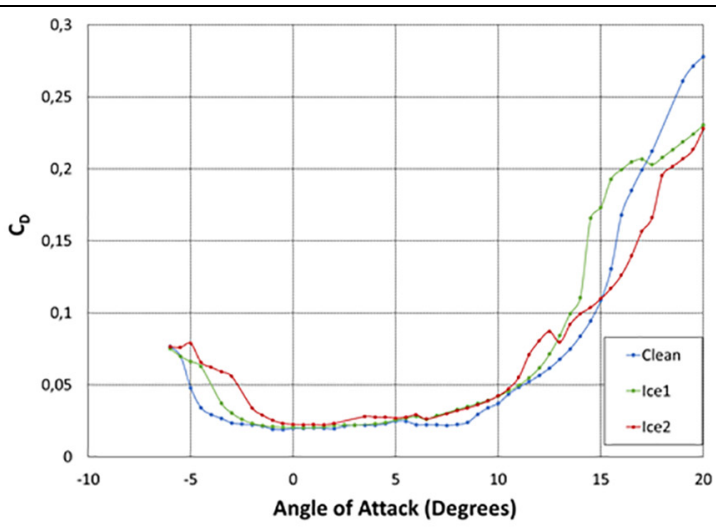

(b) Drag coefficient

Figure 6. Lift and drag coefficient versus angle of attack.

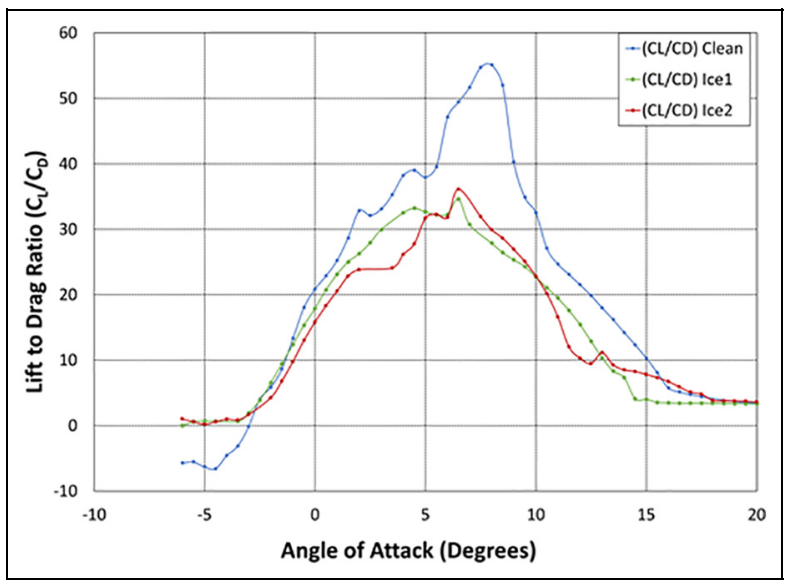

Figure 7. Lift to drag ratio versus angle of attack.

Figure 8 illustrates the evolution of the power coefficient according to the tip speed ratio. The maximum value of the power coefficient 0.421 was given by the clean profile for a tip speed ratio equal to 7.5. Concerning Ice 1 and Ice 2, the $C_{\mathrm{P}}$ values decrease and are quite close for a TSR varying between 4.5 and 7 .

A comparison of the airfoil pressure curves was done at a Reynolds number of $10^{5}$. Figure 9 presents the pressure distribution coefficient on the lower and upper side of the clean and the two presentations of the frozen NACA 4412 profile as a function of position on the airfoil for an angle of attack (AoA) equal to $8.5^{\circ}$. On the top 


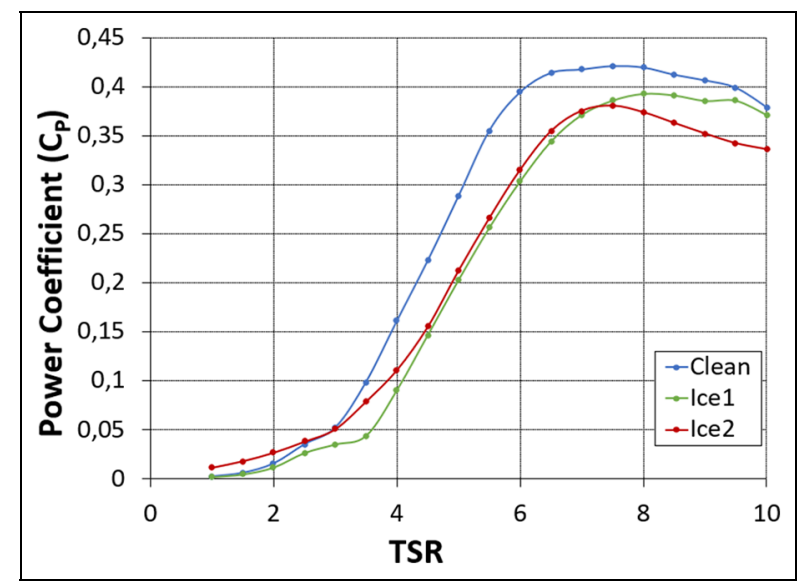

Figure 8. Power coefficient versus tip speed ratio.

Table I. Chord along the blade.

\begin{tabular}{lll}
\hline Distance from the root $(\mathrm{m})$ & Chord $(\mathrm{m})$ & Twist angle $\left(^{\circ}\right)$ \\
\hline 1.6 & 2.5 & 13 \\
4 & 2.67 & 13 \\
6 & 3.00 & 12.4 \\
8.6 & 3.54 & 12 \\
10.6 & 3.90 & 11.6 \\
14.6 & 3.57 & 10 \\
17.6 & 3.42 & 8 \\
21.6 & 3.1 & 6 \\
25.6 & 2.89 & 4.8 \\
29.6 & 2.48 & 4.03 \\
33.6 & 2.17 & 3.44 \\
37.6 & 1.86 & 3 \\
40.6 & 1.63 & 2.5 \\
42.6 & 1.47 & 1.9 \\
45.6 & 1.2 & 1.1 \\
47 & 1.00 & 0.6 \\
48 & 0.89 & 0.2 \\
\hline
\end{tabular}

surface, the strong depression near the leading edge of the profile is evident, which is much less than the pressure on the bottom surface.

It is visible that slight pressure fluctuations are occurring on both Ice 1 and Ice 2 profiles. There is also seen a difference between the different curves because of the distribution of ice formed on the leading edge. The shape of the boundary layer of the different profiles is shown in Figure 10. It can be visualized that for the clean profile, the boundary layer separation point on the top surface of the airfoil is very near to the trailing edge. As opposed to the iced profiles, the thickness of the boundary layer is increasing which can engender catastrophic effects on the lifetime of the blade, causing the phenomenon of stall, vibration and fatigue.

\section{Structural performances analysis}

The formation of ice on the blade surface represents a major risk to its structural integrity. The distribution of ice along the structure is not homogenous. It is concentrated more precisely at the tip of the blade. Icing is responsible for the deterioration of the geometry due to the accumulation of ice which produces small fissures and premature delamination in the material of the wind turbine (Afzal and Virk, 2018). 


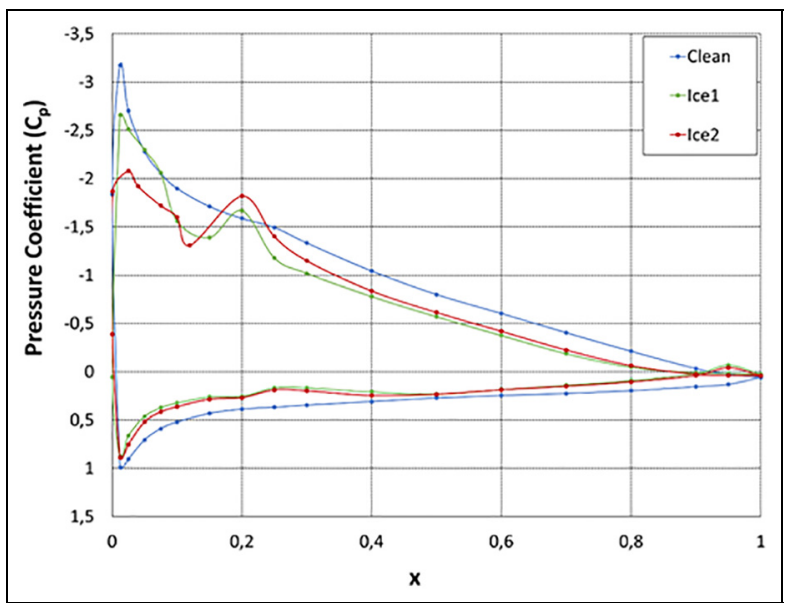

Figure 9. Distribution of pressure coefficient of clean and iced NACA 4412 at $A \circ A=8.5^{\circ}$ and $\operatorname{Re}=10^{5}$.

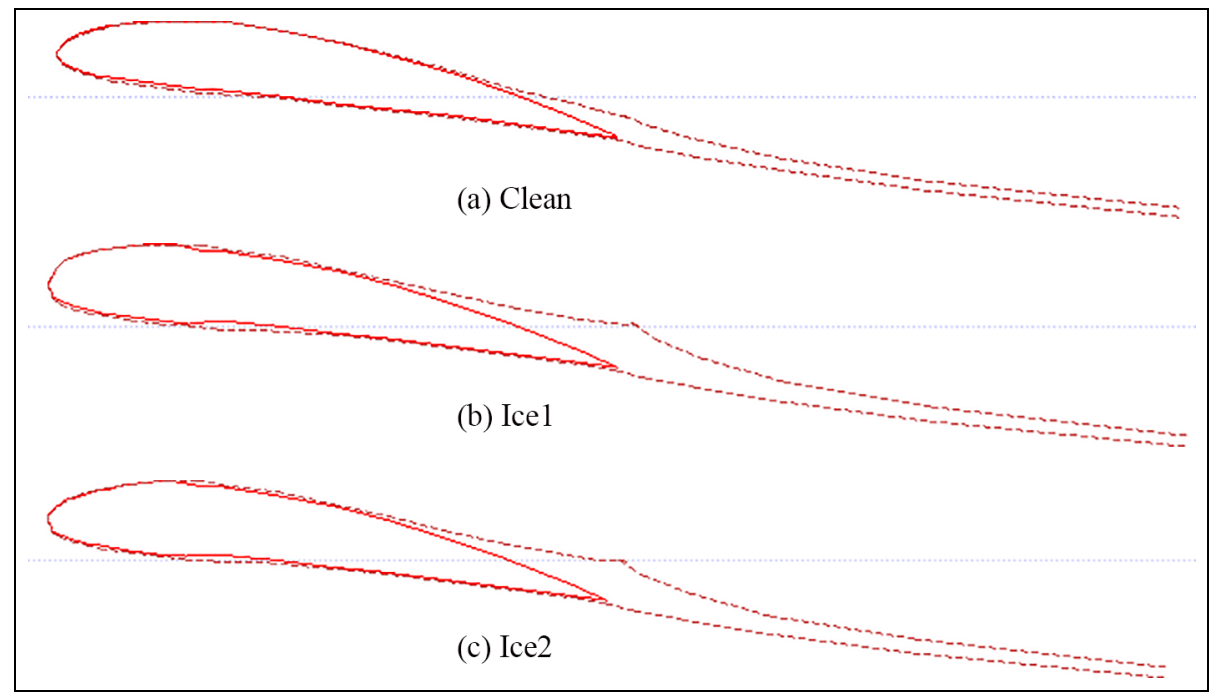

Figure 10. Boundary layer and the separation point for $A \circ A=8.5^{\circ}$.

\section{Blade description}

The considered model is a $48 \mathrm{~m}$ long of an industrial offshore wind turbine blade composed by a NACA 4412 profile with different chords, using conventional shell elements (Tarfaoui and Shah, 2013). Blade structure is made from composite fabrics reinforced with continuous fibers and are constructed from several parts as shown in Figure 11 (Fetfatsidis et al., 2012).

\section{Mechanical properties description}

The application of composite materials has progressed considerably, particularly in the construction of wind turbine blades (Rajad et al., 2018). High stiffness, excellent corrosion resistance and low weight justify the choice of these materials in our study (Nachtane et al., 2020a). The objective of this section is to analyze the behavior of the blade using Carbon and Glass fibers, whose properties are specified in Table 2. 


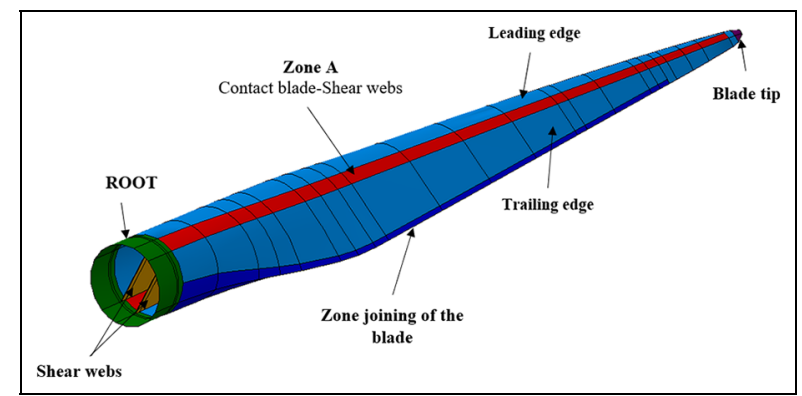

Figure II. Division of basic rotor blade geometry.

Table 2. Mechanical properties of the materials employed in the analysis of wind turbine blade.

\begin{tabular}{lll}
\hline Material property parameters & Carbon-epoxy $($ Gemi, 20I8) & Glass-polyester (Nachtane et al., 20I8) \\
\hline$\rho\left(\mathrm{kg} / \mathrm{m}^{3}\right)$ & 1600 & 1960 \\
$E_{1}(\mathrm{GPa})$ & 147 & 48.16 \\
$E_{2}(\mathrm{GPa})=E_{3}(\mathrm{GPa})$ & 10.3 & 11.210 \\
$\mathrm{Nu}_{12}=\mathrm{Nu} 13$ & 0.27 & 0.270 \\
$\mathrm{Nu}_{23}$ & 0.54 & 0.096 \\
$G_{12}(\mathrm{GPa})=G_{13}(\mathrm{GPa})$ & 7 & 4.420 \\
$G_{23}(\mathrm{GPa})$ & 3.7 & 9 \\
\hline
\end{tabular}

Table 3. Ice layer information.

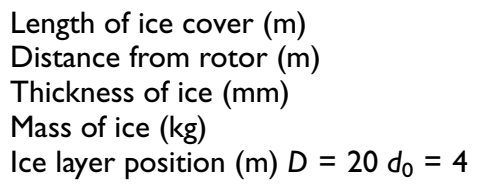

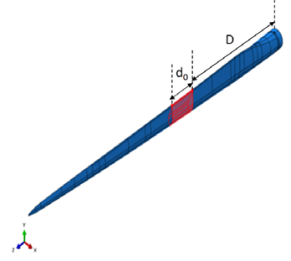

\section{FE model description and failure criterion}

Finite element modeling. Three principal loads were applied at the same time using the ABAQUS software. A wind turbine in service subjected to all critical loads is represented in Figure 12, where the green and the violet arrows indicate respectively the centrifugal and aerodynamic force while a yellow arrow is the gravity load (Tarfaoui et al., 2018). The effect of ice is analyzed at three different locations and for a vertical blade pointing upwards and downwards, Table 3 and Figure 13.

In our study, the results of the numerical study were performed by fixing the root of the rotor blade and leaving the tip free. To provide better analysis, the point at the blade tip is chosen as reference.

Hashin failure theory. To describe and detect different failure modes, damage surface is identified according to Hashin's criteria which used to prevent the initiation of structural damage in unidirectional composites (Hassoon et al., 2017; Tarfaoui et al. 2019). Four typical failure modes are considered, namely the fiber tension/compression and matrix tension/compression ( $\mathrm{Yu}$ et al., 2018). The damage started when one or more of all these mechanisms are equal to or greater than 1.0 according to the material strengths (Jared et al., 2017). Damage initiation criteria must be defined for the four modes and have the following general form, Table 4. 


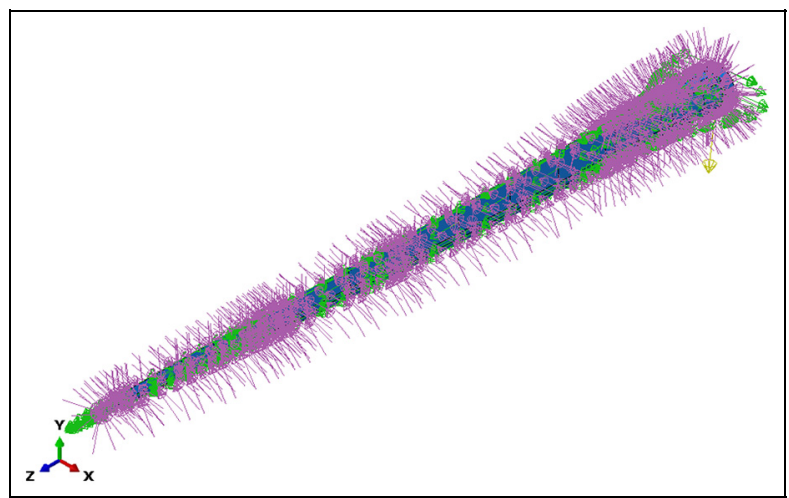

Figure 12. Wind turbine blade under all loads.

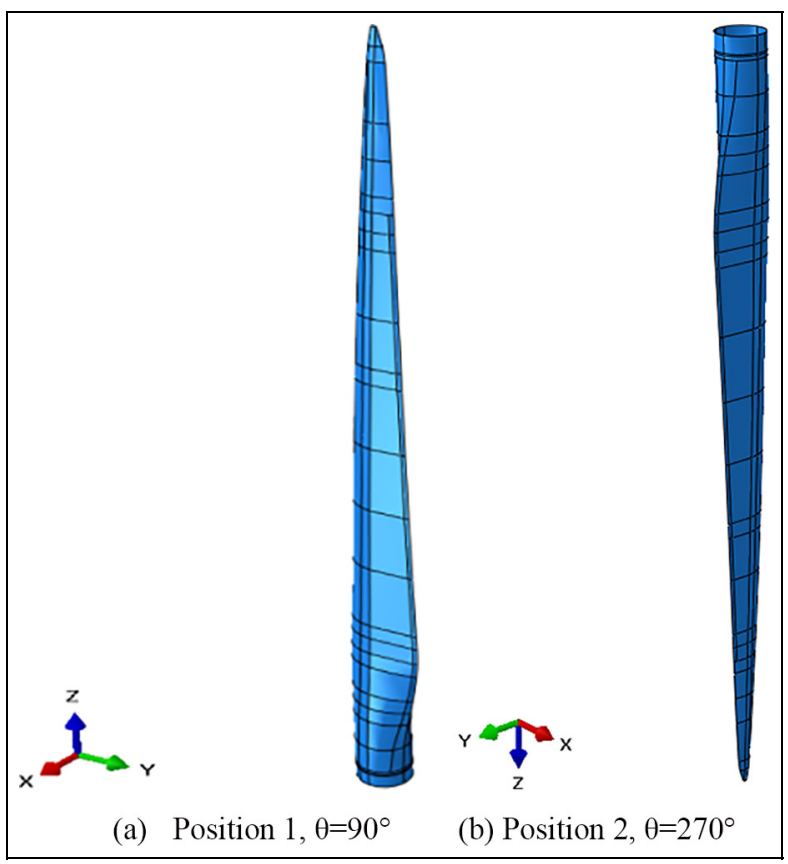

Figure 13. Schematic of different blade angles for the stationary condition.

After the damage initiation criterion has been achieved, damage evolution equations are employed to predict the diminution of material stiffness coefficients resulting from the evolution of damage (Frappier, 2016). It can be illustrated for each mode in fiber and matrix in the form below:

$$
d=\frac{\delta_{e q}^{f}\left(\delta_{e q}-\delta_{e q}^{0}\right)}{\delta_{e q}\left(\delta_{e q}^{f}-\delta_{e q}^{0}\right)}, \delta_{e q}^{0} \leqslant \delta_{e q} \leqslant \delta_{e q}^{f}
$$

$\delta_{e q}^{0}$ represents the equivalent displacement at which the initiation criterion is achieved and $\delta_{e q}^{f}$ correspond to the equivalent displacement at which the material is entirely damaged ( $d=1$; Lapczyk and Hurtado 2007).

\section{Material effect}

Various numerical simulations were executed to visualize the effect of composite materials on the behavior of an iced blade with a thickness of $100 \mathrm{~mm}$, employing each time Carbon and Glass fibers, and also to see the effect of the hybrid Carbon-Glass (CGG) situated in section A of a Carbon blade as illustrated previously in Figure 11. 
Table 4. Formulation of Hashin's criteria (Tarfaoui et al., 2019).

\begin{tabular}{ll}
\hline Fiber tension, $\hat{\sigma}_{11} \geqslant 0$ & $\left(\frac{\hat{\sigma}_{11}}{X^{T}}\right)^{2}+\alpha \times\left(\frac{\hat{\tau}_{12}}{S^{L}}\right)^{2}=F_{f}^{t}$ \\
Fiber compression, $\hat{\sigma}_{11}<0$ & $\left(\frac{\hat{\sigma}_{11}}{X^{c}}\right)^{2}=F_{f}^{c}$ \\
Matrix tension, $\hat{\sigma}_{22} \geqslant 0$ & $\left(\frac{\hat{\sigma}_{22}}{Y^{T}}\right)^{2}+\left(\frac{\hat{\tau}_{12}}{S^{L}}\right)^{2}=F_{m}^{t}$ \\
Matrix compression, $\hat{\sigma}_{22}<0$ & $\left(\frac{\hat{\sigma}_{22}}{2 S^{T}}\right)^{2}+\left[\left(\frac{Y^{c}}{2 S^{T}}\right)^{2}-1\right] \times \frac{\hat{\sigma}_{22}}{Y^{c}}+\left(\frac{\hat{\tau}_{12}}{S^{L}}\right)^{2}=F_{m}^{c}$ \\
\hline
\end{tabular}

Where in the above equations:

$X^{\top}$ is the longitudinal tensile strength,

$X^{C}$ is the longitudinal compressive strength,

$Y^{\top}$ and $Y^{C}$ designate the transverse tensile and compressive strength respectively,

$S_{\mathrm{L}}$ and $S_{\mathrm{T}}$ represents the longitudinal and transverse shear strength of the ply, respectively. $\hat{\sigma}_{11}, \hat{\sigma}_{22}, \hat{\tau}_{12}$ defines the components of an effective stress tensor and $\alpha$ is the contribution of shear stress to the fiber tensile initiation criterion (Nachtane et al., 20I7).

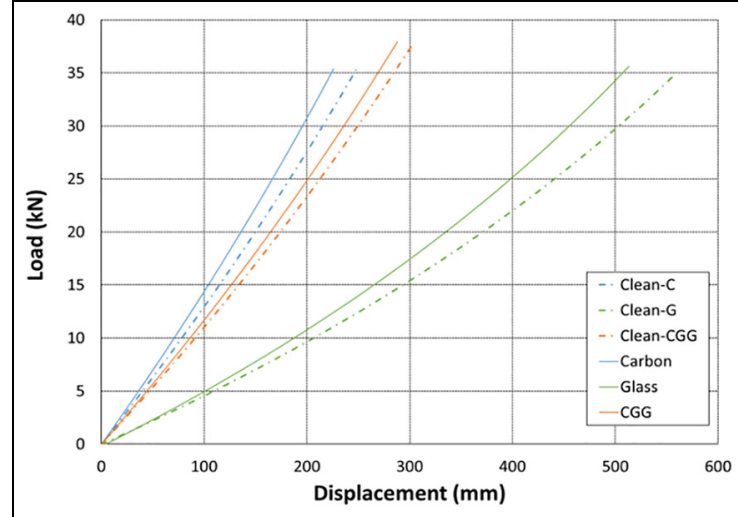

(a) Position 1, Dismax $=561.463 \mathrm{~mm}$

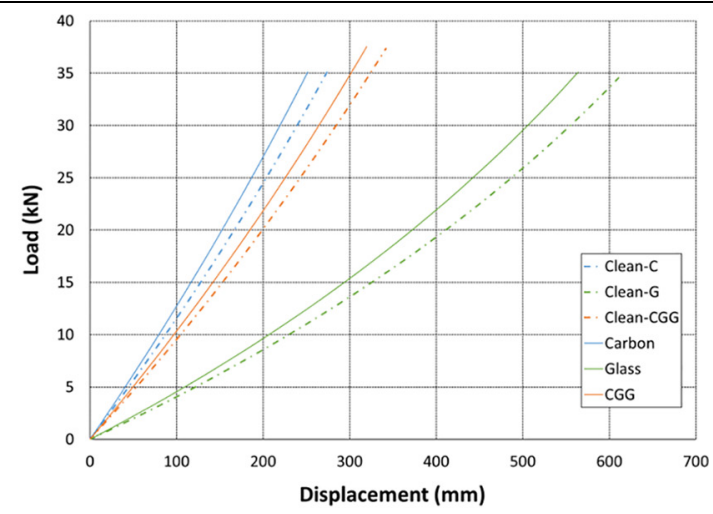

(b) Position 2, Dismax $=606.694 \mathrm{~mm}$

Figure 14. Mechanical behavior of the clean and iced composite blade.

Figure 14 represents the load-displacement curves for two different cases of an iced and un-iced blade. Position 1 is noted when the rotor is vertical pointing upwards $\left(\theta=90^{\circ}\right)$ and position 2 when it is vertical pointing downwards $\left(\theta=270^{\circ}\right)$.

One noticed that the curves of Figure 14(a) and (b) have a similar shape and the same behavior. It can be observed that Carbon has usually low maximum displacement values in comparison with other materials caused by the supplementary weight of the ice layer added to the structure. $248.21 \mathrm{~mm}$ was detected for the carbon clean blade (Clean-C) and $225.94 \mathrm{~mm}$ for the iced blade at position 1 and 273.955 and $251.825 \mathrm{~mm}$ for, respectively, un-iced and iced rotor at position 2.

The maximum stiffness was varied depending on the material and the position of the blade. A structure in Carbon gives the highest value $\left(1.565 \times 10^{5} \mathrm{~N} / \mathrm{m}\right)$, this is due to its high rigidity and strength when the ice accretion occurs on a vertical blade pointing upwards, Figure 15.

\section{Effect of the blade position}

Two different positions were evaluated and compared in this section to determine the most restrictive position (which generates the most load on the blade and / or the wind turbine) of a composite blade considering an ice thickness of $100 \mathrm{~mm}$ using Carbon fibers, Glass fibers and the hybrid Carbon-Glass (CGG), Figure 16.

According to Figure 16 and Table 5, it's shown that the highest maximum displacement value $(513.114 \mathrm{~mm})$ and a maximum force equal to $35.7687 \mathrm{kN}$ are generated by Glass fibers iced blade when the rotor tip is upward (position 1). 


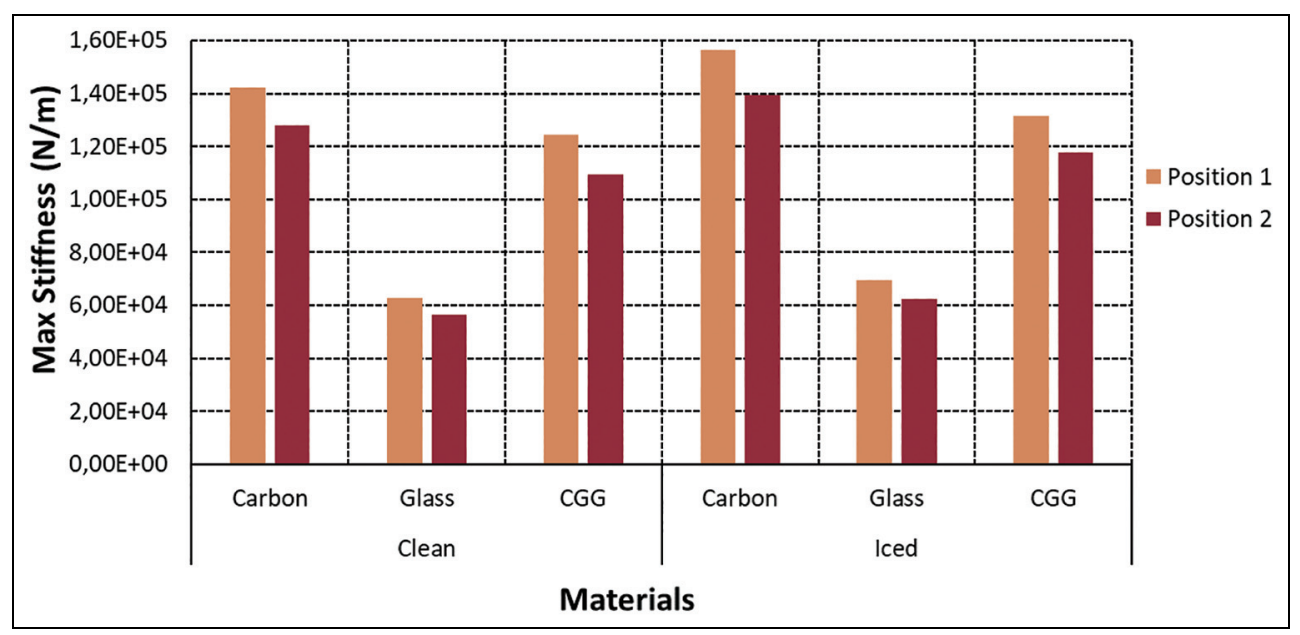

Figure I5. Maximum stiffness of the iced composite blade for different materials.

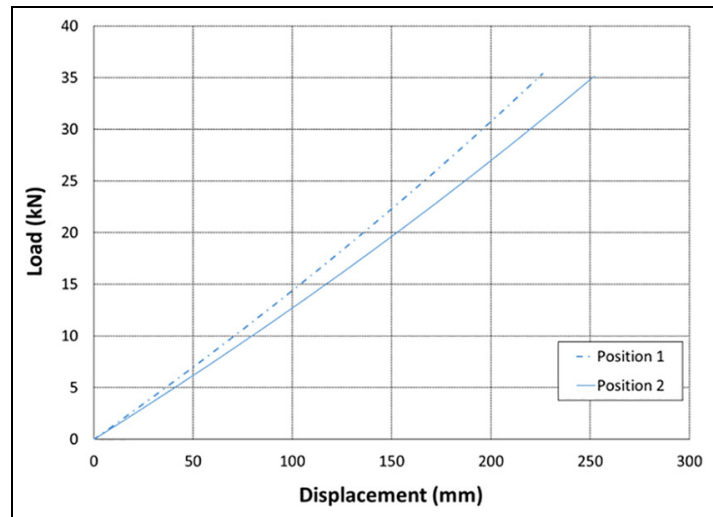

(a) Carbon

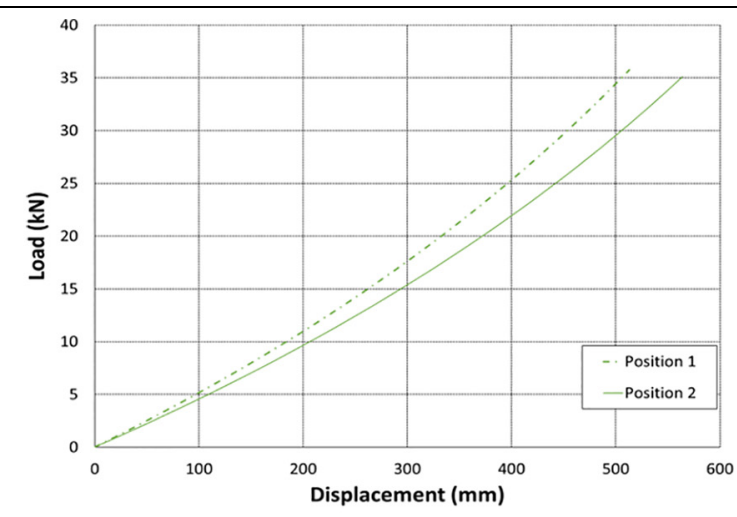

(b) Glass

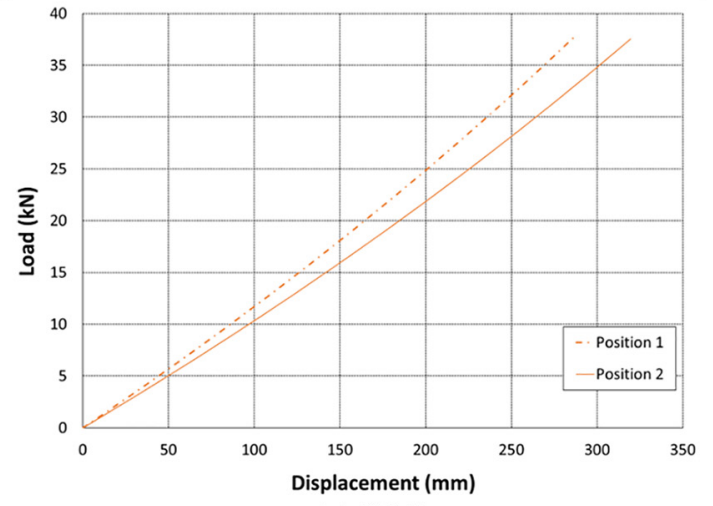

(c) CGG

Figure 16. Effect of the blade position for different materials.

When the rotor tip is downward (position 2), the maximum displacement and maximum force are, respectively, $564.073 \mathrm{~mm}$ and $35.0907 \mathrm{kN}$.

It is then concluded that position 1 generates the least load/stress on the blade because it gives lower maximum displacement and higher maximum force despite the material changes. 
Table 5. Maximum displacement and load of the composite wind turbine blade at position I and 2 .

\begin{tabular}{|c|c|c|c|c|c|c|}
\hline & \multicolumn{3}{|c|}{ Max displacement $(\mathrm{mm})$} & \multicolumn{3}{|c|}{ Max load $(\mathrm{kN})$} \\
\hline & Carbon & Glass & CGG & Carbon & Glass & CGG \\
\hline Position I & 225.94 & 513.114 & 288 & 35.3752 & 35.7687 & 37.9355 \\
\hline Position 2 & 251.825 & 564.073 & 319.596 & 35.118 & 35.0907 & 37.565 \\
\hline
\end{tabular}

Table 6. Hashin failure data of the two positions of the iced composite blade.

\begin{tabular}{llllll}
\hline & & HSNFCCRT & HSNFTCRT & HSNMCCRT & HSNMTCRT \\
\hline Carbon & Position I & $1.47 \mathrm{E}-03$ & $6.90 \mathrm{E}-03$ & $2.05 \mathrm{E}-02$ & $4.90 \mathrm{E}-02$ \\
& Position 2 & $1.67 \mathrm{E}-03$ & $7.88 \mathrm{E}-03$ & $2.44 \mathrm{E}-02$ & $5.60 \mathrm{E}-02$ \\
Glass & Position I & $2.85 \mathrm{E}-03$ & $1.21 \mathrm{E}-02$ & $1.05 \mathrm{E}-01$ & $9.15 \mathrm{E}-01$ \\
& Position 2 & $3.21 \mathrm{E}-03$ & $1.38 \mathrm{E}-02$ & $1.22 \mathrm{E}-01$ & $1.00 \mathrm{E}+00$ \\
CGG & Position I & $1.64 \mathrm{E}-03$ & $7.58 \mathrm{E}-03$ & $2.28 \mathrm{E}-02$ & $1.07 \mathrm{E}-01$ \\
& Position 2 & $1.85 \mathrm{E}-03$ & $8.63 \mathrm{E}-03$ & $2.74 \mathrm{E}-02$ & $1.43 \mathrm{E}-01$ \\
\hline
\end{tabular}

Table 7. Hashin failure data of the two positions of the clean composite blade.

\begin{tabular}{llllll}
\hline & & HSNFCCRT & HSNFTCRT & HSNMCCRT & HSNMTCRT \\
\hline Carbon & Position I & $1.5 I \mathrm{E}-03$ & $7.07 \mathrm{E}-03$ & $2.1 \mathrm{IE}-02$ & $5.03 \mathrm{E}-02$ \\
& Position 2 & $1.64 \mathrm{E}-03$ & $7.77 \mathrm{E}-03$ & $2.40 \mathrm{E}-02$ & $5.52 \mathrm{E}-02$ \\
Glass & Position I & $2.89 \mathrm{E}-03$ & $1.23 \mathrm{E}-02$ & $1.07 \mathrm{E}-01$ & $9.28 \mathrm{E}-01$ \\
& Position 2 & $3.15 \mathrm{E}-03$ & $1.35 \mathrm{E}-02$ & $1.19 \mathrm{E}-01$ & $1.00 \mathrm{E}+00$ \\
CGG & Position I & $1.67 \mathrm{E}-03$ & $7.7 \mathrm{E}-03$ & $2.33 \mathrm{E}-02$ & $1.10 \mathrm{E}-01$ \\
& Position 2 & $1.82 \mathrm{E}-03$ & $8.45 \mathrm{E}-03$ & $2.67 \mathrm{E}-02$ & $1.39 \mathrm{E}-01$ \\
\hline
\end{tabular}

From the detailed results of the numerical analysis in Table 6, it can be detected that HSNMTCRT has achieved a value of 1 for a Glass fibers material which means that damage has occurred. However, the other values of the criteria were in the order of $10^{-1}$ to $10^{-3}$, indicating that the failure was not significant.

A comparison of Tables 6 and 7 shows that the ice does not damage the blade due to its thin thickness of $100 \mathrm{~mm}$ and that the only damage appeared at the root region of the wind turbine composite blade which is represented by the red color in Figure 17 and indicates that the failure behavior is detected in this section. This is mainly attributed to transition in the thickness of the blade assembly section and the hub. Moreover, the adhesive element is responsible for the damages that appear in the bonding area of the spar with the lower or upper surface (intrados and extrados).

\section{Conclusion}

The principal goal of this research is to study the aerodynamic and structural performance of offshore wind turbine blade subject to atmospheric icing conditions. Firstly, the aerodynamic analysis of NACA 4412 profile was obtained using QBlade software for a clean and ice-accreted two-dimensional profile. The results indicated that the presence of ice reduces the lift coefficient and increases the drag coefficient and subsequently leading to a diminution in power output. Then, the structural analysis of a wind turbine blade of $48 \mathrm{~m}$ in service with $100 \mathrm{~mm}$ ice thickness is investigated using a finite element analysis with ABAQUS software. Two composite materials and two different blade positions were considered in this section. As a result of the ice accumulation on the blade, Carbon fibers have been indicated as the most resistant material and Position $1\left(\theta=90^{\circ}\right)$ proves to be the best because it gives lower maximum displacement and higher maximum force regardless of material changes. Ice does 


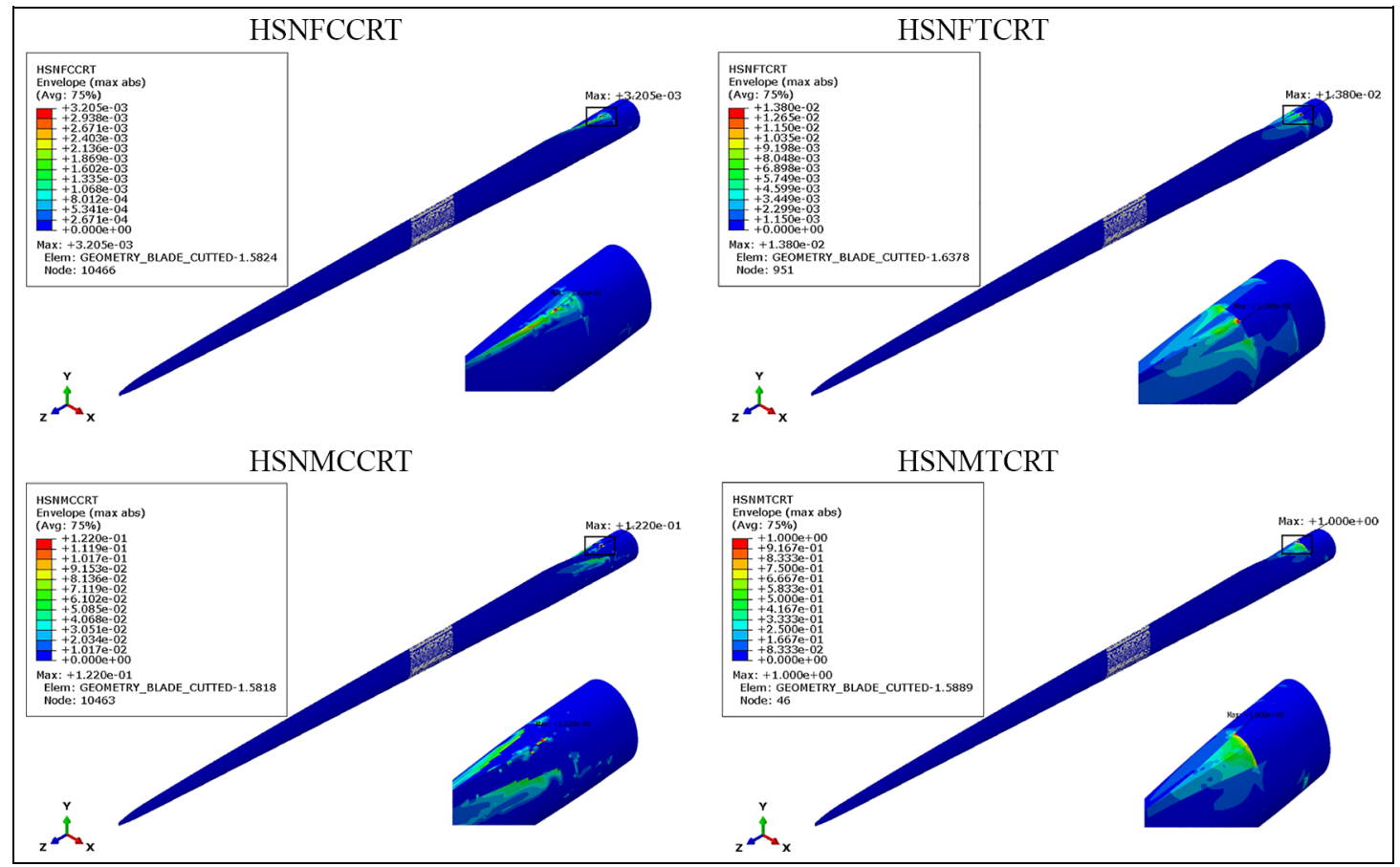

Figure I7. Hashin's criterion of the iced composite glass blade, position 2.

not damage the blade due to its thin thickness of $100 \mathrm{~mm}$. The sensitive zone for all failure criteria was in the blade root where the stresses were concentrated due to the thickness transitions and subsequently had to be reinforced.

\section{Declaration of conflicting interests}

The author(s) declared no potential conflicts of interest with respect to the research, authorship, and/or publication of this article.

\section{Funding}

The author(s) received no financial support for the research, authorship, and/or publication of this article.

\section{ORCID iD}

Oumnia Lagdani iD https://orcid.org/0000-0002-5182-9340

\section{References}

Afzal F and Virk MS (2018) Review of icing effects on wind turbine in cold regions. In: E3S Web of Conferences, vol. 72, p.01007. Tokyo, Japan, 01 - 03 June. Published by EDP Sciences. https://doi.org/10.1051/e3sconf/20187201007

Brown CM (2013) Computational modeling of rotor blade performance degradation due to ice accretion. A Thesis in Aerospace Engineering at The Pennsylvania State University the Graduate School.

Ebrahimi A, Hajipour M and Hasheminasab H (2016) Experimental investigation on the aerodynamic performance of NLF0414 iced-airfoil. Journal of Applied Fluid Mechanics 9: 587-592.

Fetfatsidis KA, Soteropoulos D, Petrov A, et al. (2012) Using abaqus/explicit to link the manufacturing process to the final part quality for continuous fiber-reinforced composite fabrics. In: Simulia community conference. Rhode Island, May 15-17.

Frappier AM (2016) An investigation of composite failure analyses and damage evolution in finite element models. A Thesis Submitted to the Faculty of Purdue University.

Gemi L (2018) Investigation of the effect of stacking sequence on low velocity impact response and damage formation in hybrid composite pipes under internal pressure. A comparative study. Composites Part B: Engineering 153: $217-232$.

Han Y and Palacios J (2012) Analytical and experimental determination of airfoil performance degradation due to ice accretion. In: Proceedings of the 4th AIAA atmospheric and space environment conference, AIAA-2012-2794, New Orleans, Louisiana. AIAA. https://doi.org/10.2514/6.2012-2794 
Hassoon OH, Tarfaoui M, El Malki Alaoui A, et al. (2017) Experimental and numerical investigation on the dynamic response of sandwich composite panels under hydrodynamic slamming loads. Composite Structures 178: 297-307.

Homola MC, Virk MS, Nicklasson PJ, et al. (2011) Performance losses due to ice accretion for a 5 MW wind turbine. Wind Energy 15(3): 379-389.

Hudecz A, Koss H and Hansen MOL (2013). Ice accretion on wind turbine blades. In: Proceedings of the 15th international workshop on atmospheric icing of structures (IWAIS XV), St. John's, Canada, 8-13 September 2013. https://orbit.dtu.dk/en/ publications/ice-accretion-on-wind-turbine-blades

Ibrahim GM, Pope K and Muzychka YS (2018) Effects of blade design on ice accretion for horizontal axis wind turbines. Journal of Wind Engineering and Industrial Aerodynamics 173: 39-52.

Jared WN, Trey WR and Douglas SC (2017) Effects of defects in composite wind turbine blades - Part 2: Progressive damage modeling of fiberglass-reinforced epoxy composites with manufacturing-induced waves. Wind Energy Science 2: 653-669.

Jha PK, Brillembourg D and Schmitz S (2012) Wind turbines under atmospheric icing conditions accretion modeling, aerodynamics, and control strategies for mitigating performance degradation. In: Proceedings of the 30th ASME wind energy symposium, AIAA-2012-1287, Nashville, Tennessee, 9-12 January 2012. AIAA. DOI: 10.2514/6.2012-1287.

Jin JY and Virk MS (2019a) Study of ice accretion and icing effects on aerodynamic characteristics of DU96 wind turbine blade profile. Cold Regions Science and Technology 160: 119-127.

Jin JY and Virk MS (2019b) Experimental study of ice accretion on S826 \& S832 wind turbine blade profiles. Cold Regions Science and Technology 169: 102913.

Lamraoui F, Fortin G, Benoit R, et al (2014) Atmospheric icing impact on wind turbine production. Cold Regions Science and Technology 100: 36-49.

Lapczyk I and Hurtado JA (2007) Progressive damage modeling in fiber-reinforced materials. Composites Part A: Applied Science and Manufacturing 38(11): 2333-2341.

Liu Y, Li L, Ning Z, et al. (2018). Experimental Investigation on the dynamic icing process over a rotating propeller model. Journal of Propulsion and Power 34(4): 933-946.

Nachtane M, Tarfaoui M, Ait Mohammed M, et al. (2020a) Effects of environmental exposure on the mechanical properties of composite tidal current turbine. Renewable Energy 156: 1132-1145.

Nachtane M, Tarfaoui M, El Moumen A, et al. (2019) Design and hydrodynamic performance of a horizontal axis hydrokinetic turbine. International Journal of Automotive and Mechanical Engineering 16: 6453-6469.

Nachtane M, Tarfaoui M, El Moumen A, et al. (2017) Damage prediction of horizontal axis marine current turbines under hydrodynamic, hydrostatic and impacts loads. Composite Structures 170: 146-157.

Nachtane M, Tarfaoui M, Saifaoui D, et al. (2018) Evaluation of durability of composite materials applied to renewable marine energy: Case of ducted tidal turbine. Energy Reports 4: 31-40.

Nachtane M, Tarfaoui M, Saifaoui D, et al. (2020b) Hydrodynamic performance evaluation of a new hydrofoil design for marine current turbines. Materials Today: Proceedings. 30(4): 889-898.

Rajad O, Hamid M, Fertah SD, et al. (2018) Fiber orientation effect on the behavior of the composite materials of the horizontal axis wind turbine blade (HAWTB). In: Proceedings of 2018 th international renewable and sustainable energy conference, IRSEC, Rabat, Morocco, 5-8 December 2018, pp.1-6. IEEE. DOI: 10.1109/IRSEC.2018.8702930

Shu L, Li H, Hu Q, et al. (2018) Study of ice accretion feature and power characteristics of wind turbines at natural icing environment. Cold Regions Science and Technology 147: 45-54.

Stoyanov DB and Nixon JD (2020) Alternative operational strategies for wind turbines in cold climates. Renewable Energy 145: 2694-2706.

Tarfaoui M, Nachtane M, Khadimallah H, et al. (2018) Simulation of mechanical behavior and damage of a large composite wind turbine blade under critical loads. Applied Composite Materials 25: 237-254.

Tarfaoui M and Shah OR (2013) Spar shape optimization of a multi megawatts composite wind turbine blade: modal analysis. In: B Attaf (ed.) Recent Advances in Composite Materials for Wind Turbine Blades, The World Academic Publishing Co. Ltd, pp.93-104.

Tarfaoui M, Shah OR and Nachtane M (2019) Design and optimization of composite offshore wind turbine blades. Journal of Energy Resources Technology 141: 051204.

Yilmaz M, Koten H, Çetinkaya E, et al. (2018) A comparative CFD analysis of NACA0012 and NACA4412 airfoils. Journal of Energy Systems 2: 145-159.

Yirtici O, Tuncer IH and Ozgen S (2017) Aerodynamic shape optimization of wind turbine blades for reducing power production losses due to ice accretion. In: 35th wind energy symposium Grapevine, Texas, 9-13 Januray 2017. AIAA. https://doi.org/ 10.2514/6.2017-1850

Yu G, Ren Y, Zhang T, et al. (2018) Hashin failure theory based damage assessment methodology of composite tidal turbine blades and implications for the blade design. China Ocean Engineering 32: 216-25.

Zanon A, De Gennaro M and Kühnelt H (2018) Wind energy harnessing of the NREL 5 MW reference wind turbine in icing conditions under different operational strategies. Renewable Energy 115: 760-772. 